\title{
Establishing a Reading Culture in a Rural Secondary School: A Literacy Intervention with Teachers
}

Journal of Asian and African Studies $0(0) \mathrm{I}-14$

(C) The Author(s) 2013

Reprints and permissions: sagepub.co.uk/journalsPermissions.nav DOI: $10.1177 / 0021909613487676$ jas.sagepub.com

(S)AGE

\author{
Ina Joubert \\ Department of Education, University of Pretoria, South Africa
}

\section{Liesel Ebersöhn}

Department of Educational Psychology, University of Pretoria, South Africa

\section{Ronel Ferreira}

Department of Educational Psychology, University of Pretoria, South Africa

\author{
Loraine du Plessis \\ Department of Early Childhood Education, University of Pretoria, South Africa
}

\section{Melanie Moen}

Department of Education, University of Pretoria, South Africa

\begin{abstract}
The purpose of this study was to explore and describe the nature of a reading culture in a rural secondary school in South Africa before and after a literacy intervention. The systems theory with interpretivism as the epistemological paradigm was employed. A rural secondary school was selected as part of an on-going Flourishing Learning Youth and Supportive Teachers Assets and Resilience studies on resilience and rural schools. Language teachers $(n=6$, male $=1$, female $=5)$ were purposively selected to participate. The literacy intervention was developed with phonetic acquisition as the basis to develop reading skills. It became evident that implementing English (additional language) as teaching and learning language in the school may have contributed to barriers to learning. Limited resources and reading instruction training exacerbated the problems. However, once the teachers acquired new skills and the children received the needed support, the improvement in overall academic achievement was significant.
\end{abstract}

\section{Keywords}

Reading culture, literacy intervention, teachers, children, rural secondary school, school structures, systems theory

\section{Corresponding author:}

Ina Joubert, Department of Early Childhood Education, Faculty of Education, University of Pretoria, Pretoria 0002,

South Africa.

Email: ina.joubert@up.ac.za 


\section{Introduction}

In South Africa, it is estimated that between 7.4 and 8.5 million adults are illiterate and between 2.9 and 4.2 million people have never formally attended school (UNESCO, 2002). One million South African children reportedly live in households in which no one has the ability to read (UNESCO, 2002). Wienand (2011) reports in his study that more than $70 \%$ of South African children at a national level have difficulties learning to read, while Blank (2006) states that the figure for children with learning difficulties in America is $40 \%$. Evidently, reading appears to be a problem for children internationally, but it is cause for concern that a significantly higher level of South African children are experiencing barriers to reading.

Habitual reading is the foundation of a reading culture. Whitehurst (2002: 11) states that children who read well, read more, which gives them the opportunity to acquire more knowledge in numerous domains. However, as indicated earlier, learning to read continues to be a barrier to learning not only in the South African school system, but also in a global context (Shaw and Davidson, 2009). Kachala (2007) states that poor delivery of information services in rural areas contributes strongly not only to lower levels of educational standards, but also to lower levels of literacy. These obstacles are exacerbated in schools in rural settings. Kachala (2007) notes further that the separation between developed and developing nations is placing rural areas at a disadvantage concerning access to relevant and timely information.

A reading culture could ensure that children are well equipped to excel in their studies, thereby improving the standards of education in rural areas (Kachala, 2007). Teaching reading in schools depends mostly on two main methods, namely phonetics and the whole-language approach (Blank, 2006). Phonetics acquisition forms a platform from which development of reading skills can take place. Therefore, in order to surmount the barriers that children may experience in phonetic acquisition, a phonetic intervention programme can be introduced (Adonis and Huges, 2007). The central point of reading-phonetics is the adaptation of letters into sounds, whereas the whole-language approach introduces the more conventional methods of teaching reading that focus on word recognition of words when reading. These conventional methods include factors such as reading motivation (Blank, 2006).

The teacher, school and community play a vital role in assisting a child to learn to read, as well as to use this skill on a habitual basis, thus developing and maintaining a reading culture. Teachers face an extremely challenging task when teaching a child to read and are expected to include a vast number of attributes, such as phonological awareness, phonics, spelling, fluency, language knowledge, comprehension, cognitive strategies and reading excessively (Blank, 2006). Children who do not read well by Grade 3 are more likely to have poor reading abilities throughout their lifetime (Blank, 2006). It is important to note this, as the teacher-participants of the selected school teach older secondary school children who are already challenged by a lack of general reading skills.

According to Whitehurst (2002), learning to read is a key milestone for children living in a literate society. As the lack of reading was identified as one of the problems at the participating school, the focus was on implementing and maintaining a reading culture in the school. The school is situated in Elukwatini, a rural area in Mpumalanga, South Africa. The majority of the children in the school spoke SiSwati (first or home language) and, according to the teachers, the children's English (additional language) language skills were underdeveloped. The children used English mainly as their language of learning in the classrooms, as it is the language of learning and teaching of the school. The children did not demonstrate much enthusiasm towards reading, which may be considered a plausible reason for delay in the development of a reading culture in the school. The teachers at the participating school spoke a variety of African languages, such as Sepedi, Shona, Setswana and Shangaan. A number of the teachers at the school did not speak SiSwati, resulting in a challenge to provide children with the needed teaching assistance in their first language or 
home language. Therefore, the teachers voiced their need for guidance to assist the children in developing their English literacy skills in order to create and maintain a reading culture at the school. The following research question framed the research project:

To what extent can a literacy intervention with teachers in a rural secondary school inform and enhance the reading culture in the school?

\section{Defining a reading culture}

A reading culture can be defined as 'the collective attitudes, beliefs, and behaviours of all the stakeholders in a school regarding any and all of the activities associated, which enables all learners to read at the highest level of attainment for both their academic and personal gain' (McEwan, 2002). Another essential aspect of a reading culture is highlighted in the definition of Doiron and Asselin (2010), in which they imply that the optimum situation would be one 'where reading is regarded not simply as something developed for school purposes but something practiced in all aspects of our lives.'

In relation to this study, a reading culture signifies attitudes, beliefs and behaviours that enable reading in the following systems: learners, teachers, school and community in all the activities associated with reading that enable learners to read on a regular basis, which in turn will deepen such a culture and make it sustainable.

\section{Second-language acquisition}

In recent decades, a remarkable interest has been shown in second-language acquisition, which includes reading skills, because of the rapid internationalisation of business and industry together with continual immigration influences (Long and Richards, 2005).

Language researchers continue to debate the reason for older children having trouble in the acquisition of reading skills in a second language. Older children and adults proceed faster through syntactic and morphological development than younger learners. However, children beginning a second-language acquisition before puberty often achieve a higher proficiency level than individuals beginning as adolescents (Killfoil and Van Der Walt, 2007). Some researchers feel that older children have the advantage of using their first-language experiences. Acquiring reading skills in a second language thus implies that some basic linguistic foundation has formed. Kraschen (2002) concludes that older children or adults acquiring a second language may fall back on their first language influences because of low or minimal acquisition of the target language.

When learning to read a second language, learners focus more on establishing a linguistic foundation at first than focusing on decoding (Koda, 2005). Therefore, acquiring a basic linguistic foundation is pivotal. When learning to read, children draw on both first and second languages in order to read; therefore, both first and second languages are interrelated when learning to read a second language. In this study the second language was English.

Another challenge in this study was the rural setting. Gardiner (2008) states that rural areas typically have shortcomings regardless of their potential. In rural school settings, socio-economic conditions generally refer to poverty, employment redundancy, the lack of access to water, transportation, basic services and electricity (Gardiner, 2008). These influences also include the conflicting demands of the school and parents concerning children's domestic and educational obligations.

Meganathan (2009) states that rural schools are faced with challenges in terms of teacher proficiency and training, which affects a reading culture. Teachers face various challenges as their qualifications are often questioned, their accents are misunderstood, they have inadequate subject 
knowledge, inadequate communication and a lack of instructional material. According to a 2004 national study of language competency in South Africa, over $60 \%$ of children could read at the acceptable level for their grade (Department of Education, 2008). This result was to a certain extent ascribed to the fact that teachers beyond the first two grades of primary school were inadequately trained to teach basic reading (Department of Education, 2008).

Children are faced with many challenges when learning a second language and often have to face a lack of resources, inadequately trained teachers, poverty and their own motivation, as well as demands from home.

\section{Research site}

A rural secondary school in Mpumalanga, South Africa, was identified for this study. The school forms part of two long-term research projects conducted by Supportive Teachers Assets and Resilience (STAR) and Flourishing Learning Youth (FLY) projects.

According to Wienand (2011), the former Department of Education (DOE) identified learning barriers in rural schools to be a lack of appropriate facilities and infrastructure, poor access to textbooks and resources, a lack of qualified teachers and good quality leadership, and safety in and around schools, as well as overcrowded classrooms and difficulty with discipline. The rural school in this study also encountered some of the barriers mentioned by Wienand: the teachers at the school were not trained to teach (secondary school) learners to read, and the school was isolated and scarce-resourced in nature. Limited reading material was available to the children.

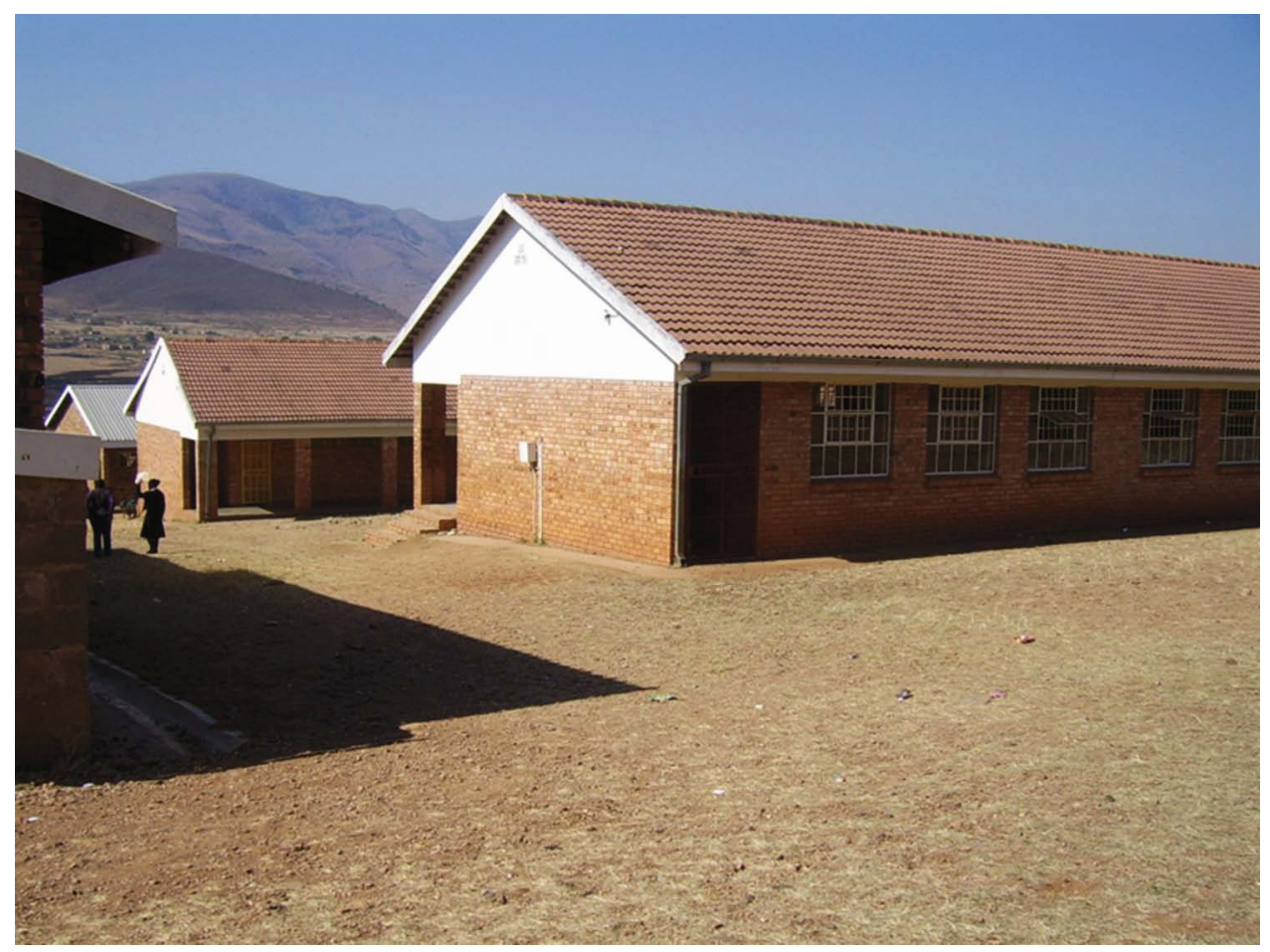

Picture I. The School 


\section{Methodology}

An intervention research design to draw on experiences, theory and data was used in order to develop a literacy intervention (Fraser et al., 2009). Intervention research implies the application of a theory-based and systematic approach in order to generate ideas through the process of documenting possible intervention strategies, assessing effectiveness and disseminating findings (De Vos, 2005; Fraser et al., 2009) in striving to improve people's lives to some extent (Hohmann and Shear, 2002: 202).

De Vos (2005) identify three main phases of intervention research, namely intervention knowledge development, knowledge utilisation and design and development. Intervention knowledge development implies a process of gaining knowledge about human behaviour. The intervention knowledge development formed part of 'Phase 1: Getting started' in the interactive cycle of actionreflection. During this phase, knowledge was gained in order to define problems identified at the secondary school by partnering with teachers to seek common understanding of the defined problems. Knowledge utilisation refers to the practical implication of the knowledge gained during the knowledge development phase, which formed part of 'Phase 3: Building partnership' in the interactive cycle of action-reflection. During this phase, the necessary data and information were collected in order to develop a shared understanding of the problems identified during Phase 1. Design and development, which imply the conversion of the knowledge learned into an applicable innovative intervention, form part of 'Phase 5: Working together' in the interactive cycle of action-reflection. During this phase, the knowledge learned was applied in order to create and implement a literacy intervention programme at the selected school. The selection of the participating school was delimited to the setting in which the study took place. It was selected partly for the sake of convenience (Creswell, 2009; Hay, 2005; Maree and Pietersen, 2007: 183), since current STAR and FLY projects were already taking place there. An additional criterion for delimited selection was the availability of appointed language teachers to participate in the intervention, as well as the school's willingness to participate in the study.

\section{Sample}

From a qualitative interpretive perspective of inquiry, convenience sampling to select teachers based on their participation in the FLY and STAR projects was used. The participants were mandated by the Head of the Language Department of the secondary school to participate. As such, teachers were selected based on their availability, as well as their involvement in literacy or reading at the school. This led to the selection of six literacy teachers $(n=6$, male $=1$, female $=5)$ for Grades 7-12.

\section{Developing the intervention}

A literacy intervention programme was implemented to provide the teachers with the necessary literacy training in order to assist the children. For the purpose of this study, a literacy intervention strategy was implemented with the teachers. Three focus group discussions were conducted over two days with the six teachers to inform and develop a literacy intervention programme to implement with the children. The two pre-intervention focus group discussions were held in a classroom and in the library. During this time, two observations to gain insight into the requirements for the development of a literacy intervention programme took place. The children in the school struggled with reading, writing and speaking English. The language of learning and teaching was an additional language for both learners and teachers and it was therefore important to include the teachers 
in the basic language skills programme, starting with the phonetic approach. The programme was therefore designed for teachers and children alike.

Relevant literature was consulted to create an understanding of possible literacy interventions that could have an ameliorating impact on a deficient reading culture. A literacy intervention programme was developed, which incorporated two phases. Both the first and second stages contained an adapted phonetic programme. Stage 1 of the intervention programme was implemented over one day and focused on basic phonetic training through the introduction of single-syllable words and sounds. The second stage of the intervention programme was introduced over one day and focused on more advanced phonetic training, introducing double-syllable words and sounds. Postintervention observation sessions at the rural secondary school in striving to understand the reading culture took place following a literacy intervention.

The activities in the intervention programme in this study were aimed at educating teachers regarding phonics in order to teach English with the aim to develop and maintain a reading culture at school. A basic phonetic programme was chosen because this approach is used in basic adult literacy training in South Africa. This approach was also chosen to encourage both teachers and children to start reading and to experience reading as a successful and enjoyable activity.

\section{Data collection}

Textual documents to assess the nature of the reading culture at the secondary school were collected before and after the literacy intervention. Textual documents in the form of primary public documents and minutes of meetings at which reading problems experienced at the selected school were discussed, as well as Grade 7 English term marks, were collected.

Observations of classroom activities and the school environment, as well as the intervention implementation, were made. The observations were repeated after the implementation of the literacy intervention. The goal of these observations was to understand the culture, setting and social relationships among the participating teachers at the school in order to understand the reading culture before and after the implementation of a literacy intervention.

Observations were documented by means of field notes. The content of the field notes included observations that were made, as well as personal ideas that occurred to the researchers in the field.

Photographs and audio-visual recordings to document observation were used. Photographs were used to document the research setting, the classrooms and school environment, as well as the presented literacy intervention implemented at the selected school. This assisted the researcher to document details regarding the settings as well as specific factual data needed. A research journal was also used to write down the researcher's ideas, challenges and outcomes. Journaling was used in collaboration with other data and proved valuable in supporting the findings.

Focus group interviews were used to gather data through exploring the discourses that outline the practices of everyday life surrounding this research. Three focus group interviews (Hay, 2005; Nieuwenhuis, 2007) were conducted. The first focus group interviews were held before the implementation of the intervention programme. The second focus group meeting took place after the intervention programme was implemented. The aim of the first focus group was to discuss the current reading culture (or lack thereof) at the selected secondary school. The outcome of the focus group discussion led to the development and implementation of the literacy intervention programme. The aim of the third focus group discussion was to determine whether any changes had occurred after the implementation of the literacy intervention. The focus group interviews lasted approximately one hour each and were conducted on site at the school. The focus group discussions were audio-recorded and later transcribed (Nieuwenhuis, 2007). Field notes and visual data 
in the form of photographs were used as secondary methods of capturing the data collected during the focus group interviews.

Furthermore, the researchers engaged in informal conversational interviews with several of the participating teachers. Cohen et al. (2000) explain that such interviews, because of their informal and non-directive nature, constitute an interviewing strategy that allows for a more relaxed, flexible approach as the questions emerge from the direct situation in which participants and interviewers find themselves.

\section{Data analysis}

The six phases of thematic analysis suggested by Braun and Clark (2006: 87) were used to analyse the data.

$\begin{array}{ll}\text { Phase one: } & \text { Familiarisation of data } \\ \text { Phase two: } & \text { Coding data } \\ \text { Phase three: } & \text { Identifying patterns } \\ \text { Phase four: } & \text { Review themes } \\ \text { Phase five: } & \text { Define and name themes identified } \\ \text { Phase six: } & \text { Produce and report findings }\end{array}$

During the first phase, the focus group discussions, observational data and field notes were described. This phase implied reading and re-reading the selected textual data and transcribing important ideas. In the second phase the selected data was coded by using coding schemes (Mertler, 2006) in order to simplify correlations between the data. In the third phase, patterns were observed to identify themes across the selected data.

After identifying initial themes, the next phase (four) of reviewing these identified themes followed. This step ensured that the themes identified during the third phase matched the codes identified in phase two in order to generate a chart of overall themes. As the themes were identified phase five was completed, which implied defining and naming each theme identified during phase four. The process was concluded by compiling a report of the findings, as well as reviewing these findings.

\section{Discussion}

In this section, the contributions of the teachers, school structures and children to the reading culture in the rural secondary school before and after a literacy intervention are described.

\section{Teachers' contribution to the reading culture before and after a literacy intervention}

Before the literacy intervention, the participating teachers expressed the view that the use of an additional language (English) as the language of learning and teaching impacted negatively on the reading culture. They were furthermore of the opinion that communication between them and the children was stymied, which influenced discussions around reading negatively. The teachers also expressed feelings of incompetence in teaching children how to read, since training in literacy skills did not form part of their Further Education and Training Phase programmes. These feelings exacerbated a sense of frustration among the teachers, because the secondary school children were 
not able to read at the grade-appropriate level. Participating teachers viewed this inability to read as a further barrier to promoting a reading culture in classrooms. Children's lack of engagement also appeared to have a negative influence on teachers' attitudes towards them. Despite all of these obstacles, the teachers were still motivated to acquire the knowledge and skills for enabling them to support children in reading. This was evident in the teachers' efforts to make best use of the limited available resources to motivate reading (for example by sharing four textbooks among children in one reading period).

After the literacy intervention, teachers not only expressed confidence in their abilities to teach secondary school children how to read, but were also able to assist children in honing their reading skills. Some of the reading strategies teachers used at post-intervention were to implement literacy intervention activities, such as homework exercises, introducing peer teaching during reading, using extracts from textbooks to create opportunities for children to read aloud during class time, and allowing children to ask for guidance if they were not able to understand texts.

When the former DOE supplied more textbooks to the school, the teachers used these to great effect during reading classes. Children became more engaged during reading activities and teachers responded positively towards the children by expressing their pride in the children's progress. Teachers were also central to implementing reading periods - as stipulated by the principal in response to a DOE national initiative. Teachers also contributed to an expanded reading culture by initiating a partnership with fellow teachers in nearby primary schools.

\section{Children's contribution to the reading culture before and after a literacy intervention}

Before the literacy intervention, the children also experienced language barriers because of the prominence of English in the school. This was deemed a significant factor in determining children's contribution to a reading culture. Most of the children in this study were not proficient in English and presented with communication barriers and consequently underperformed academically. The children's lack of proficiency in English thus had a detrimental effect on their ability to contribute constructively to a reading culture in the school.

A major rationale for the literacy intervention was that participating teachers were concerned about the fact that their secondary school children had inadequate reading abilities. The children also lacked motivation, as was evident in their negative attitudes (distraction and lack of interest and engagement) towards reading. Besides the children's inability to read, their lack of reading motivation was exacerbated by factors such as a lack of reading resources (textbooks, library books) and the teachers' lack of training in literacy guidance.

After the literacy intervention, teachers reported an overall improvement in the children's language abilities. According to the teachers involved in this study, the improved language abilities were evident not only in more active participation during classes, but also in the children's confidence to read (during classes, and borrowing from the library). Teachers reported that the children's academic achievement (in both Mathematics and English) improved, possibly because of their enhanced reading confidence and the ability to read with comprehension. One of the children could not write his name before the intervention and was able to do so after. One teacher commented that after the literacy programme there was a remarkable improvement in the children's reading and spelling abilities. It was also observed by some teachers that the children's vocabulary and comprehension improved, the work was understood better and the children started interacting in the classroom more frequently. Some teachers also commented that sounding the alphabet helped children to read difficult words. 


\section{The school structures before and after a literacy intervention}

At both pre- and post-intervention, the selected school had limited resources and was isolated from support functions, such as teacher training and service provision by the former DOE.

Before the literacy intervention, the school had a minimally resourced library that was little used by children. A particular teacher was tasked with managing the library, which lacked proper operating procedures (logbook, lending procedures, library rules). The school leadership often discussed their concern regarding the children's inability to read. The leadership structures attempted to improve reading by advocating and supporting initiatives to promote the reading culture of the school.

The post-intervention reading culture scenario was influenced positively by education system actions. In this regard, two initiatives by the former DOE enriched the reading culture (irrespective of the presence or absence of the literacy intervention). In the first instance, a reading period was indicated nationally for schools. Secondly, the schools received English textbooks for languageclass instruction. The school principal was a key member in implementing these education sector initiatives in partnership with the teachers.

After the literacy intervention and upgrading of the facilities, the library seemed to be accessed more frequently by children, as was reported by teachers and indicated in the logbook. In addition, the library started including a logbook and visible library rules, as well as procedures for booklending. The library teacher observed that after the programme the children brought back books and borrowed more. One teacher commented that after the intervention programme the children wanted to read more without the help of the teacher and she observed a change in their behaviour. The school also extended the scope of the reading culture by networking with neighbouring schools for joint capacity development.

\section{The literacy intervention with teachers: informing a reading culture at the school}

General systems theory was used to illustrate (in Figures 1 and 2) the reading culture before and after the implementation of a literacy intervention. General systems theory was adopted as a theoretical framework, since the theory complements the nature of the study. This perspective focuses on the concept of inter-connection; it identifies individuals as part of a system in which they interact with one another (Arthur, 2005; Avis, 2004). Donald et al. (2009) adds that the performance of the entire system is therefore dependent on the interaction between all parts. In this study there were various interrelated systems involved. The learners' and teachers' systems are dependent not only on each other in the successful implementation and maintenance of reading culture, but also on the classroom system, rural community system, educational sector and policies system, the South African system and, lastly, the world system. These systems are dependent on each other for their successful functioning and, consequently, for the effective implementation of a reading culture. The basic assumptions embedded in general systems theory are applicable to this study, implying that a literacy intervention implemented in one of the systems will have an effect on the entire system (Avis, 2004). A literacy intervention with teachers may thus possibly create a reading culture in the school and flow over into the community as well. Figure 1 illustrates the reading culture systems in the selected school before the literacy intervention. Figure 2 illustrates the reading culture systems in the school after the literacy intervention.

In Figure 1, it is apparent that in the particular rural secondary school (school system) the children (children system) struggled to read. The teachers and principal (broader governance school system) requested initiatives to promote reading and related learning support to enhance the 


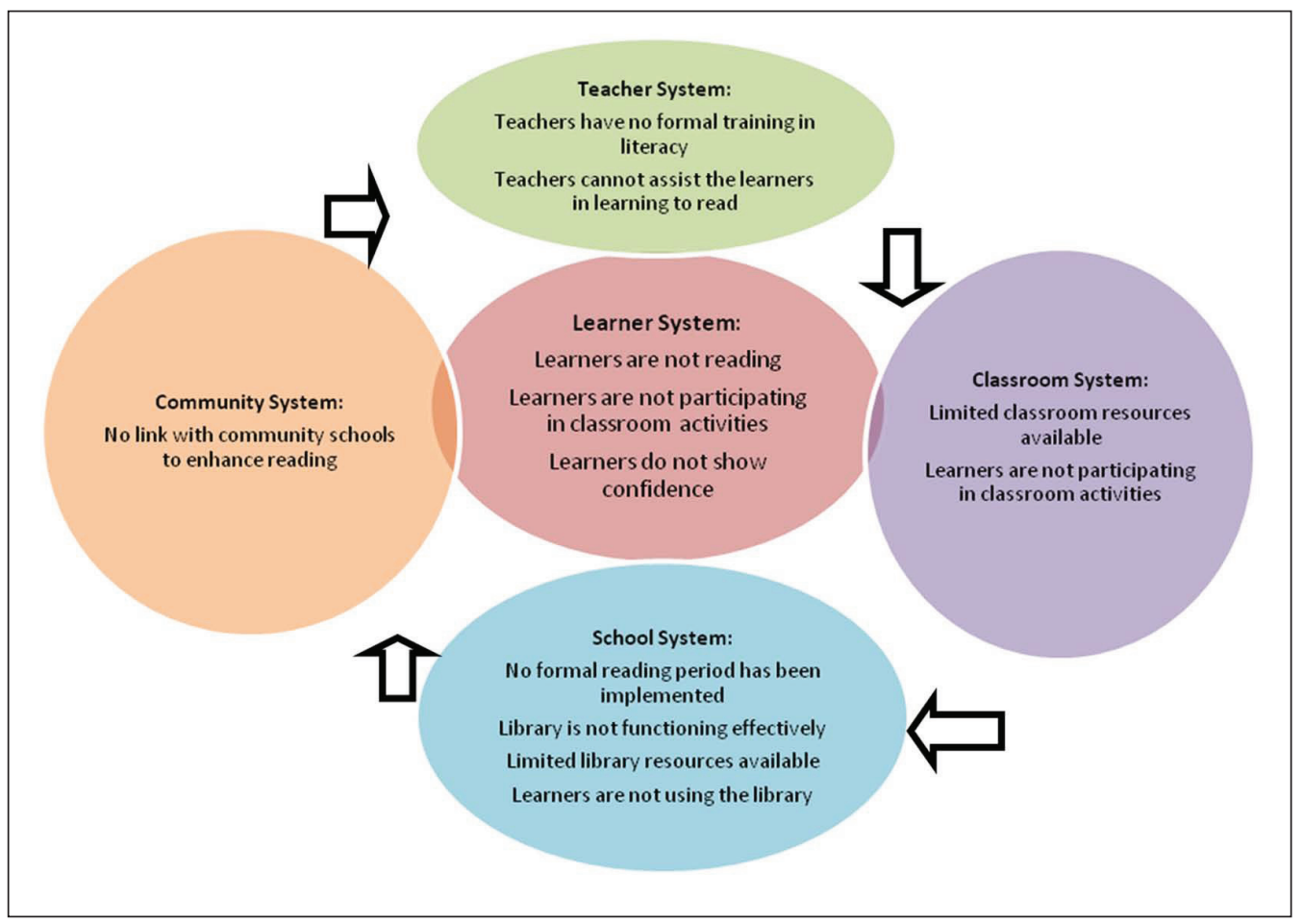

Figure I. Pre-intervention systems.

reading culture. Prior to the intervention, the teachers (teacher system) lacked the necessary skills to teach the children (children system) to read. As a result, the teachers (teacher system) could not provide the children (children system) with the required literacy support to teach them to read. The reading difficulties that the children (children system) experienced were exacerbated by their problems with communicating in English (the language of learning and teaching) with teachers (teacher system) in classrooms (classroom system) and in school activities (school system). Most of the children could not speak, read or write English adequately, negatively influencing their ability to learn and perform well academically. Furthermore, the children did not actively participate due to low confidence and motivation in reading as an activity in the classroom system. The lack of engagement in the classroom system between children and teachers possibly demonstrated the children's limited confidence in English and their own reading abilities. The children's limited confidence plausibly links with their lack of reading motivation. The lack of reading resources, such as textbooks and reading books in the classroom and school system, most likely also had a detrimental effect on the children system.

At pre-intervention, children rarely made use of the library (school system). The library was functioning without systems to regulate lending and library use. The shortage of library resources, especially reading books, also affected the functionally of the library negatively, as limited reading material was available to invite children to read. At the community-system level, networks to articulate the reading culture between primary schools and the secondary school also did not exist.

Figure 2 illustrates the teachers' (teacher system) participation in a literacy intervention, focusing on phonic skills to provide learning support to the children's (children system) reading. As a 


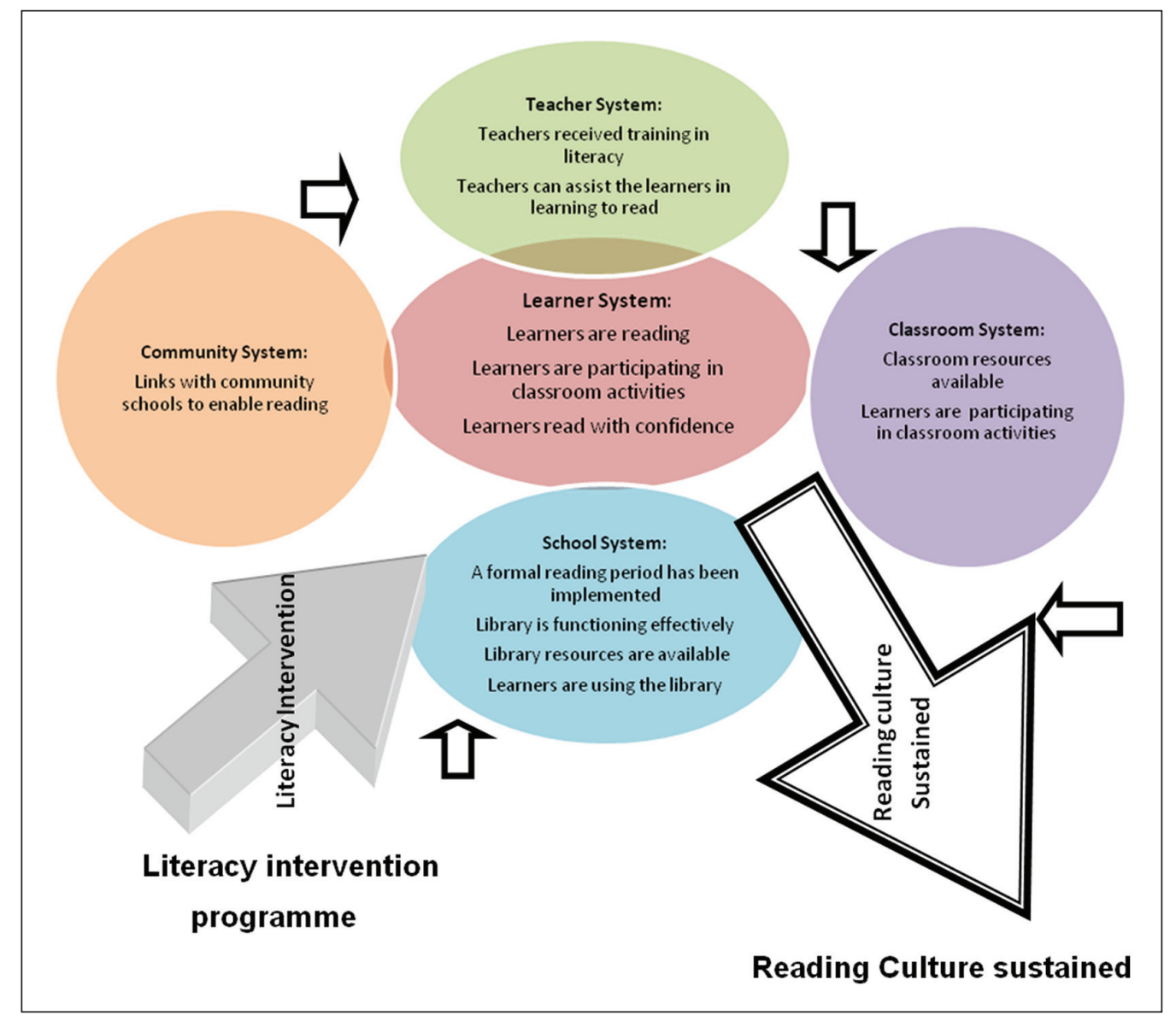

Figure 2. Post-intervention systems.

result, the teachers (teacher system) were able to assist children (children system) to read in the classroom system. It was evident that interaction in the classroom system changed with children being more involved. Teachers also reported an improvement in the children's language abilities and their academic achievement, especially in English and Mathematics. Children were not only more willing to communicate, but also reportedly read with more confidence and displayed a greater interest in reading (reading motivation). Children made use of the library more often (as indicated in the logbook in the library). Reciprocally, at post-intervention the library (school system) had procedures for lending books, library rules, and a logbook. In the broader education sector system, a formal reading period was mandated. This policy decision was implemented at school level, making it possible for the teachers and children to have a set time to energise the reading culture. In the community system, the secondary school collaborated with two neighbouring primary schools to participate in the literacy intervention, thereby constituting an inclusive reading culture among the schools.

In conclusion, it became apparent from this research that when rural secondary school teachers know how to teach reading it appears to influence a reading culture in the school system positively. 
When teachers participated in a literacy intervention, the teacher system changed as teachers were provided with literacy skills to assist children to read. Partnering with rural secondary school teachers to gain knowledge on literacy also affected the children system. Children became engaged in classroom reading activities, were able to read with more confidence and thus were more motivated to read. Reciprocally, this children system change also had a beneficial effect on the teacher system, since teachers became more positive towards children. The initial school-system initiative to implement a literacy intervention with teachers thus held multiple benefits for a variety of reading culture systems. The breadth of the systemic influence also extended to the reading cultures of two neighbouring rural primary schools.

\section{Limitations of the study}

A limited sample was used as only one rural secondary school was part of this study; however, the aim was to gain insight into the phenomenon at a specific school in a specific context. Convenience sampling was used, and it cannot be assumed that the participants of this study were representative of a population, although there might be transferability to similar cases.

This study did not include a pilot phase, and consequently the literacy intervention was not introduced in other rural secondary schools with similar participating teachers. This could be regarded as a limitation; however, the selected teachers have been involved in on-going research projects (STAR and FLY) at the selected school. A pilot study was therefore not implemented, as the intervention merely assisted in understanding a reading culture before and after the literacy intervention at the specific school.

The fact that not all the participating teachers were fluent in English at times hindered their ability to articulate themselves well. These language limitations could possibly have influenced the quality and interpretation of the data collected.

\section{Conclusion}

The establishment of a reading culture among children, as previously mentioned, remains a problem not only in South Africa, but also internationally. In this study, it became evident that the choice of implementing English as language of learning and teaching in this specific secondary school may have contributed to children struggling with an additional language. It can be concluded that the language created a barrier to the children regarding easy linguistic-conceptual access to learning materials and modes. The problem was exacerbated in this rural secondary school in which teachers, because of limited reading instruction (literacy) training, were impeded in their ability to teach the secondary school children basic reading skills.

The rural secondary school context further compounded this problem, since the availability of resources was limited and training opportunities were hard to come by in such a setting. However, research indicated that teachers were determined to acquire skills to assist children in reading. In their turn, children seemed eager to learn to read when they were provided with the needed support and guidance. Consequently, after relevant literacy training, teachers made use of paired reading strategies, the library and activities from the given literacy intervention programme to assist children to read. Once the children received the needed support in being taught to read, they read more regularly (in classes and by using the library more frequently). This seemed to have a positive impact on their overall academic achievement.

Although the participating rural school was isolated and poorly resourced, the systematic enhancement of a reading culture included a well-managed library system and enabling school 
structures for the implementation of policy initiatives aimed at fostering reading skills. By sustaining and reinforcing such a reading culture, it is possible that mutual support among the various relevant systems could contribute greatly to surmounting the barriers by way of nurturing a reading culture in the school.

\section{Funding}

This research received no specific grant from any funding agency in the public, commercial or not-for-profit sectors.

\section{References}

Adonis A and Huges B (2007) Letters and sound principles and practice of high quality phonics. Available at: http://www.letters-and-sounds.com (accessed 29 April 2010).

Arthur N (2005) Multicultural career counceling: Theoretical application of the Systems Theory Framework. The Career Development Quarterly 53(3): 208-222.

Avis P (2004) Psychological Perspectives and Introductory Workbook. Cape Town: CTP Books.

Blank M (2006) The Reading Remedy. Six Essential Skills that will turn your Child into a READER. Hoboken, USA: Jossey-Bass.

Braun V and Clarke V (2006) Using thematic analysis in psychology. Qualitative Research in Psychology 3(2): 77-101.

Cohen L, Manion L and Furbush D (2000) Research Methods in Education. 5th ed. London and New York: Routledge Falmer.

Creswell J (2009) Research Design Qualitative, Quantitative, and Mixed Methods Approaches. 3rd ed. California, USA: SAGE Publisher.

De Vos (2005) Research at Grass Roots. Pretoria: Van Schaik Publishers.

Department of Education (2008) National reading strategy. Available at: http://www.info.gov.za/view/DownloadFile Action?id=78955 (accessed 2 April 2012).

Doiron R and Asselin M (2010) Building a culture for reading in a multilcultural, multilingual world. In: world library and information congress: 76th IFLA general conference and assembly, Sweden: IFLA.

Donald D, Lazarus S and Lolwana P (2009). Educational Psychology in Social Context. New York: Oxford.

Fraser M, Richman J, Calinsky M, et al. (2009) Intervention Research Developing Social Problems. Oxford: Oxford University Press.

Gardiner M (2008) Education in Rural Areas. Issues in Education Policy (4): 1-33.

Hay I (2005) Qualitative Research. Melbourne: Oxford University Press.

Hohmann A and Shear M (2002) Community-based intervention research: Coping with the "noise" of real life in study design. American Journal of Psychiatry 159(2): 201-207.

Kachala F (2007) Developing a reading culture among the rural masses of Mwambo, Zomba District, Malawi; A concept for the 21 st century and beyond. In: World library and information congress: 73 RD IFLA general conference and council, pp.1-14. Durban: WLIC.

Killfoil WR and Van Der Walt C (2007) Learn 2 Teach. English Language in a Multilingual Context. Pretoria: Van Schaik Publishers.

Koda K (2005) Insights into Second Language Reading: A Cross-Linguistic Approach. New York: Cambridge University Press.

Kraschen S (2002) Second Language Learning. California, USA: Pergamon Press Inc.

Long M and Richards J (2005) Insights into Second Language Reading, A Cross Liguistic Approach. United States of America: Cambridge University Press.

Maree K and Pietersen J (2007) Sampling. In: Maree K (ed.) First Steps in Research. Pretoria: Van Schaik Publishers.

McEwan E (2002) Teach Them All to Read, Catching the Kids Who Fall through the Cracks. California, USA: Corwing Press Inc. 
Meganathan R (2009) English Language Education in Rural Schools: The Situation, the Policy and the Curriculum. Available at: http://www.teachingenlish.org.uk/sites/teacheng/files/Z413\%20EDB\%20Section04_0.pdf (accessed 2 April 2012)

Mertler C (2006) Action Research. Teachers as Researchers in the Classroom. London: SAGE Publications. Niewenhuis J (2007) Introducing qualitative research. In Maree K (ed.) First Steps in Research. Pretoria: Van Schaiks Publishers.

Shaw M and Davidson M (2009) Using the Phono-Graphix Reading Programme as a Literacy Support Intervention Strategy. Oxford: Blackwell Publishing.

UNESCO(2002)Familyliteracyproject. Availableat:http://www.unesco.org/uil/litbase/?menu=4\&programme=43. (accessed 4 April 2012).

Whitehurst GJ (2002) Emergent literacy: Development from prereaders to readers. In Neuman SB (ed.) Handbook of Early Literacy Research. New York: The Guilford Press.

Wienand M (2011) Empowering Teachers to Render Children Support to Children who Experience Reading Barriers. Port Elizabeth: Nelson Mandela Metropolitan University.

\section{Author biographies}

Ina Joubert is a senior lecturer in the Department of Early Childhood Education, Faculty of Education, at the University of Pretoria. She specialises in citizenship and teaching English First Additional language to children.

Liesel Ebersöhn heads the Unit for Education Research in AIDS, University of Pretoria, where she is also a full professor in the Department of Educational Psychology, Faculty of Education. As a National Research Foundation-rated researcher she interrogates resilience as collective and sustained transactional-ecological processes within resource-scarce education environments.

Ronél Ferreira is head of the Department of Educational Psychology at the University of Pretoria. She is also theme leader of the Institute for Food, Nutrition and Well-being at the same institution, leading a group of researchers across faculties in an interdisciplinary research project. Her research focus areas are psychosocial support within the context of vulnerability, HIV\&AIDS, asset-based psychosocial coping and resilience, and the use of action research in combination with intervention-based studies that could improve communitybased coping. Ronél's research accomplishments are signified, amongst others, by her being a rated researcher at the South African National Research Foundation and recipient of the Samuel Henry Prince Dissertation Award of the International Sociological Association (2009).

Loraine du Plessis is a registered Educational Psychologist with language teaching and lecturing experience. She currently works as an Educational Psychologist at a primary school in Pretoria.

Melanie Moen is a researcher in the Department of Education at the University of Pretoria. She has been part of the University's Distance Education Programme since 2003. She is a registered Educational Psychologist. 